KANSAS JOURNAL of MEDICINE

\section{Intention to Read to Newborns Following a Brief Reading Promotion Intervention among Low-Income Pregnant Women}

Deshanett Clay, M.D., Carolyn R. Ahlers-Schmidt, Ph.D., Mary Benton, Ph.D., Matt Engel, MPH, Molly Brown, MPH University of Kansas School of Medicine-Wichita, Department of Pediatrics

Received October 11, 2018; Accepted for publication February 5, 2019; Published online May 15, 2019

\section{ABSTRACT}

Introduction. Reading to children can increase word knowledge and success in school. The American Academy of Pediatrics recommends beginning reading at birth. However, children from low-income families are exposed to less words, including reading exposure, than children from high-income families.

Methods. Pregnant women attending a community prenatal education program targeted at high-risk and low-income populations were recruited into this study. Participants completed a pre-survey, engaged with a brief educational intervention, then completed a matched post-survey. Surveys assessed perceived benefits, intended behaviors, and self-efficacy regarding reading to their child.

Results. Of 61 eligible participants, 54 (89\%) completed the study. Participants reported being Black (33\%), White (30\%), Hispanic (28\%), and other race (9\%). Average gestational age at enrollment was 27 weeks (range 13 to 38 weeks). The average age of respondents was 26 years $(\mathrm{SD}=7.2)$; $46 \%$ reported being pregnant for the first time. Following the intervention, no change in knowledge regarding benefits of reading was observed, however, baseline knowledge was high (58\% - 94\%). At post-test, significantly more women reported it was important to start reading to their child at birth (83\% vs $56 \%$; p $<0.001)$ and that they planned to start reading to their child at birth (70\% vs $50 \%$; $\mathrm{p}=0.001$ ).

Conclusions. A brief educational intervention showed promise in increasing pregnant women's intentions to read to their children and should be considered in conjunction with other reading promotion programs. Follow-up to assess actual reading behavior is needed.

Kans J Med 2019;12(2):50-52.

\section{INTRODUCTION}

Early delays in language development and reading comprehension decrease academic performance, especially among low-income populations. ${ }^{1,2}$ Age at onset of home reading routines is an important predictor of language skills ${ }^{3}$ and a home environment deficient in reading negatively impacts school readiness and brain development of young children. ${ }^{4}$ Further, low literacy and early academic difficulties are linked to school dropout, increased risk for stress and illness in adulthood, negative lifestyle behaviors, low self-esteem, higher unemployment rates, and poverty. ${ }^{5-7}$ The American Academy of Pediatrics (AAP) recommends that pediatric providers encourage parents to read to their children beginning in infancy. ${ }^{1,8}$
By age three, children from high-income families were estimated to hear nearly 30 million more words than those from low-income families. ${ }^{910}$ In Kansas, students who were eligible for free or reduced lunch, an indicator of low-income, were less likely to have reading assessment scores at or above basic level, proficient level, and advance level than non-eligible students ( $54 \%$ vs $84 \%, 20 \%$ vs $54 \%$, and $3 \%$ vs $16 \%$, respectively)." ${ }^{11}$ To address the gap, a brief educational intervention was developed to promote reading to infants among women attending a free prenatal educational program, called Baby Talk. Operating in six primary care clinics serving high risk mothers, the Baby Talk program is designed to promote maternal and infant health through education, on topics such as safe infant sleep, physical activity during pregnancy, stress management, smoking cessation, breastfeeding, and nutrition. ${ }^{12}$ Program attendees are predominantly from marginalized populations, including low-income and minority communities. The purpose of the present study was to evaluate the success of a brief intervention by measuring changes in perceived benefits, intended behaviors, and self-efficacy of Baby Talk participants as related to reading to their children.

\section{METHODS}

Participants. Eligible participants were pregnant women attending a Baby Talk session on infant care between January 1 and April 30, 2017. Surveys were only offered in English as Baby Talk was only offered in English at that time.

Instrument. Pre- and post-intervention surveys were designed specifically for this study as no existing instruments were identified. The surveys measured five items related to participants' perceived benefits, intention, and confidence in reading to their children. Surveys were reviewed for readability and content validity by an expert panel, including pediatric providers and researchers.

To assess perceptions of the benefits of reading to children, respondents selected from a list, including two false benefits. Open-ended questions were used to assess the age at which respondents thought it was important to start reading to their children and the age at which respondents intended to start reading to their children. Responses of 'while pregnant,' 'in the womb,' 'now', and 'newborn' were coded as zero months of age. The number of days per week $(0,1-2,3-4,5$ - 6 , 7) that respondents planned to read to their children was assessed.

Procedures. During a Baby Talk session on infant care, women were recruited into the study and verbal consent was obtained. Pre-surveys were distributed and collected upon completion. An intervention, based on the Health Belief Model (HBM), was implemented by the session facilitator. In line with HBM, the intervention addressed beliefs, perceived benefits, barriers, and self-efficacy. ${ }^{13}$ The five-minute educational intervention included a description of school readiness, a 90-second clip from the video '30 Million Word Gap', 14,15 discussion about the benefits of reading to children, strategies for establishing reading routines, and a brief reading demonstration using a board book as a prop. Information on programs such as Reach Out and Read ${ }^{15}$ and the Dolly Parton Imagination Library (https:// imaginationlibrary.com/usa/) also was provided. After the brief intervention, a matched post-survey was administered and collected upon completion. Individual participants completed all study materials 
during a single, two-hour Baby Talk class and received an infant board book for participation.

This study was approved by the Human Subjects Committee at the University of Kansas School of Medicine-Wichita.

Analysis. Survey responses were entered into REDCap ${ }^{\mathrm{Tm}}$ and results were analyzed using SPSS version 23 (IBM Corp, Armonk, NY). Categorical variables were reported in frequencies and proportions; continuous variables were reported in means and standard deviations (SD); and pre-post analysis was conducted using $\mathrm{McNe}-$ mar's test on paired surveys.

\section{RESULTS}

Sixty-one expectant mothers were approached across six Baby Talk sessions, one did not meet inclusion criteria having already delivered her infant, and six declined to participate resulting in an $89 \%$ (n $=54$ ) participation rate. The average age of participants was 26 years ( $\mathrm{SD}=7$, range 15 to 50). Participants reported being Black $(33 \% ; \mathrm{n}=$ 18), White $(30 \% ; \mathrm{n}=16)$, Hispanic $(28 \% ; \mathrm{n}=15)$, and other race $(9 \%$; $\mathrm{n}=5)$. Forty-six percent $(\mathrm{n}=25)$ reported having no other children living in the home and $7 \%(n=4)$ reported having five or more children living in the home. The average gestational age of participants at enrollment was 27 weeks (range 13 to 38 weeks).

When asked to select all benefits associated with reading prior to the intervention, almost all participants acknowledged school readiness benefits and increased vocabulary (Table 1). There was no difference in perceived benefits between the pre-and post-survey.

Following the intervention, significantly more women reported it was important to start reading to their children at birth (83\% vs $56 \%$; $<0.001)$ and they planned to start reading to their child at birth (70\% vs 50\%; $\mathrm{p}=0.001)$. One mother reported she intended to start reading to her children at age three years on both pre- and postintervention surveys. Compared to response on the pre-intervention survey, after the brief education, mothers reported they intended to read to their children more days per week $(\mathrm{p}<0.001$; Table 2$)$.

On the post-survey, $91 \%$ reported being 'more likely' to read to their children and $87 \%$ of women reported being 'more confident' in their ability to read to their children. A single respondent reported feeling 'less confident' in her ability to read to her infant.

Table 1. Perceived benefits of reading to children.

\begin{tabular}{|c|c|c|c|}
\hline Benefit & $\begin{array}{c}\text { Pre-Intervention } \\
\text { n (\%) }\end{array}$ & $\begin{array}{c}\text { Post-Intervention } \\
\text { n (\%) }\end{array}$ & p value \\
\hline Learn more words & $51(94 \%)$ & $52(96 \%)$ & 1.000 \\
\hline $\begin{array}{c}\text { Increase self- } \\
\text { esteem }\end{array}$ & $32(59 \%)$ & $39(72 \%)$ & 0.118 \\
\hline $\begin{array}{c}\text { Less behavior } \\
\text { problems }\end{array}$ & $33(61 \%)$ & $40(74 \%)$ & 0.065 \\
\hline $\begin{array}{c}\text { More successful in } \\
\text { school }\end{array}$ & $51(94 \%)$ & $52(96 \%)$ & 1.000 \\
\hline $\begin{array}{c}\text { Less likely to be } \\
\text { sick* }\end{array}$ & $3(6 \%)$ & $2(4 \%)$ & 1.000 \\
\hline Less overweight* & $3(6 \%)$ & $2(4 \%)$ & 1.000 \\
\hline
\end{tabular}

${ }^{*}$ False benefit
KANSAS JOURNAL of MEDICINE READING PROMOTION TO PREGNANT WOMEN continued.

Table 2. Number of days parent plans to read to children.

\begin{tabular}{|c|c|c|c|}
\hline $\begin{array}{c}\text { Number of days } \\
\text { per week }\end{array}$ & $\begin{array}{c}\text { Pre-Intervention } \\
\mathbf{n}(\boldsymbol{\%})\end{array}$ & $\begin{array}{c}\text { Post-Intervention } \\
\mathbf{n}(\boldsymbol{\%})\end{array}$ & $\%$ change \\
\hline $\mathbf{0}$ & $0(0 \%)$ & $0(0 \%)$ & $0 \%$ \\
\hline $\mathbf{1 - 2}$ & $6(11 \%)$ & $3(6 \%)$ & $-5 \%$ \\
\hline $\mathbf{3 - 4}$ & $23(43 \%)$ & $8(15 \%)$ & $-28 \%$ \\
\hline $\mathbf{5 - 6}$ & $10(19 \%)$ & $21(39 \%)$ & $+20 \%$ \\
\hline $\mathbf{7}$ & $15(28 \%)$ & $22(41 \%)$ & $+13 \%$ \\
\hline
\end{tabular}

\section{DISCUSSION}

The purpose of this study was to evaluate a brief intervention related to reading to infants by measuring changes in perceived benefits, intended behaviors, and self-efficacy. Results suggested a short intervention during a prenatal educational session can promote reading to infants as indicated by increased confidence and intent among low-income pregnant women. Following the intervention, significantly more Baby Talk participants reported they believed it was important to start reading at or prior to birth and voiced intention to start reading at that time. These results were consistent with other studies demonstrating improvements in parental attitudes toward the importance of reading to their young children following a reading promotion intervention. ${ }^{8,16}$ Our brief intervention significantly impacted pregnant women's beliefs, intentions, and confidence regarding reading to their children prenatally, thus presenting an even earlier attempt at intervening and promoting reading and storytelling with infants.

Reading to children stimulates optimal patterns of cortical development during critical and sensitive periods of early child development. ${ }^{8}$ Learning that takes place throughout prenatal and early postnatal neurodevelopment has a long-term effect on neural circuits and brain function. ${ }^{4}$ Children with higher levels of home reading exposure showed greater neural activation within the left-sided parietal-temporal-occipital association cortex, a region enabling mental imagery and narrative comprehension. Further, reading with children in the years before entering kindergarten is associated with increased school readiness and interest in reading as well as better health literacy and lower health risks. ${ }^{8}$

Pregnant women in this study were knowledgeable of the benefits of reading to children, even at baseline. This may explain why a difference in perceived benefits was not observed. However, in spite of understanding the benefits, less than half of participants at baseline reported plans to read to their children from birth. This is important because the vast majority of a child's early language experiences (e.g., spoken language) takes place either in the home or in a child care setting. $5,6,8$ In addition, even post-intervention, the majority of women were not moved to read to their child every day. This result might be attributed to limitations of the intervention and/or issues faced by many families (e.g., busy schedules, competition from electronic media, and toys for children's attention). ${ }^{8}$ 
KANSAS JOURNAL of MEDICINE READING PROMOTION TO PREGNANT WOMEN continued.

However, results of the current study are consistent with the low rates of parent-child reading reported by the 2000 National Survey of Early Childhood Health (NSECH). ${ }^{1}$

Limitations of the present study included an insufficient sample size to test associations between maternal characteristics and planned behaviors meaningfully, a short data collection period, and a lack of follow-up to determine if maternal planned behavior reflected actual behavior. All participants were English speaking and findings may not apply to those with a primary language other than English. Additionally, while financial status of all participants could not be verified, the broader data from the Baby Talk program reveals that the majority of participants are low-income.

\section{CONCLUSION}

Results from the present study suggested a short intervention during a prenatal educational session to promote reading to infants increased knowledge, intent, and confidence among low-income pregnant women. Given that socioeconomic status is correlated positively with reading comprehension and academic performance, ${ }^{1,2}$ these results suggested reading interventions in a low-income prenatal population are warranted and beneficial. Further research is needed to conclude whether increased knowledge, intent, and confidence among low-income pregnant women translates to a change in actual behavior. However, reading interventions should be part of a larger continuum of education, including established models for reading promotion, such as Reach Out and Read. ${ }^{15}$

\section{ACKNOWLEDGEMENT}

The authors would like to recognize Sudy Yang, M.D. for her contributions in data collection and interpretation.

\section{REFERENCES}

${ }^{1}$ Kuo AA, Franke TM, Regalado M, Halfon N. Parent report of reading to young children. Pediatrics 2004; 113(6 Suppl):1944-1951. PMID: 15173465.

${ }^{2}$ Freebody P, Ludwig C, Gunn S. Everyday literacy practices in and out of school. Brisbane, Australia: Centre for Literacy Education Research, 1995. ISBN: 0868576891.

3 Debaryshe BD. Joint picture-book reading correlates of early oral language skill. J Child Lang 1993; 20(2):455-461. PMID: 8376479.

${ }^{4}$ Hutton JS, Horowitz-Kraus T, Mendelsohn AL, DeWitt T, Holland SK, C-Mind Authorship Consortium. Home reading environment and brain activation in preschool children listening to stories. Pediatrics 2015; 136(3):466-478. PMID: 26260716.

5 Pagani LS, Fitzpatrick C. Children's school readiness: Implications for eliminating future disparities in health and education. Health Educ Behav 2014; 41(1):25-33. PMID: 23445605.

${ }^{6}$ Schoon I, Parsons S, Rush R, Law J. Childhood language skills and adult literacy: A 29-year follow-up study. Pediatrics 2010; 125(3):e459-466. PMID: 20142287.

7 High PC, LaGasse L, Becker S, Ahlgren I, Gardner A. Literacy promotion in primary care pediatrics: Can we make a difference? Pediatrics 2000; 105(4 Pt 2):927-934. PMID: 10742349.

8 Council on Early Childhood, High PC, Klass P. Literacy promotion: An essential component of primary care pediatric practice. Pediatrics 2014; 134(2):404-409. PMID: 24962987.

9 Hart B, Risley TR. The early catastrophe: The 30 million word gap by age 3. American Educator 2003; 27(1):4-9.

${ }^{10}$ Radesky JS, Carta J, Bair-Merritt M. The 30 million-word gap: Relevance for Pediatrics. JAMA Pediatr 2016; 170(9):825-826. PMID: 27379489.
${ }^{11}$ US Department of Education, Institute of Education Sciences, National Center for Education Statistics, National Assessment of Educational Progress (NAEP). 2015 Reading Assessment, Kansas, Grade 4. https://nces. ed.gov/nationsreportcard/subject/publications/stt2015/pdf/2016008KS4. pdf. Accessed August 23, 2018.

${ }_{12}$ Ahlers-Schmidt CR, Brown M, Engel M, et al. Baby Talk: Developing a community collaborative prenatal education program to support lowincome pregnant women. J Ped Moth Care 2017; 2(2):113.

${ }^{13}$ Rosenstock I. Historical origins of the Health Belief Model. Health Educ Behav 1974; 2(4):328-335.

${ }_{14}$ Books are the Beginning. 30 Million Word Gap. January 22, 2015. Available at: https://www.youtube.com/watch?v=779aFxFqrq4. Accessed August 23, 2018.

${ }_{15}$ Willis E, Kabler-Babbitt C, Zuckerman B. Early literacy interventions: Reach Out and Read. Pediatr Clin North Am 2007; 54(3):625-642. PMID: 17543913.

${ }^{16}$ Needlman R, Toker KH, Dreyer BP, Klass P, Mendelsohn AL. Effectiveness of a primary care intervention to support reading aloud: A multicenter evaluation. Ambul Pediatr 2005; 5(4):209-215. PMID: 16026185.

Keywords: reading, education, infant, pregnant women 